\title{
Dissociations Within Nondeclarative Memory in Huntington's Disease
}

\author{
Barbara J. Knowiton \\ University of California, Los Angeles
}

\author{
Larry R. Squire and Jane S. Paulsen \\ Vcterans Affairs Medical Center, San Diego, \\ and University of California, San Diego \\ Nelson Butters \\ Veterans Affairs Medical Center, San Diego, \\ and University of California, San Diego
}

\begin{abstract}
Patients with Huntington's Disease (HD) were tested on 2 tasks, probabilistic classification learning and artificial grammar learning. Both tasks are performed normally by amnesic patients and are considered to be independent of declarative memory. Patients with HD were severely impaired in probabilistic learning but performed normally in artificial grammar learning. The probabilistic classification task may be akin to habit-learning tasks that depend on the neostriatum, whereas artificial grammar learning may depend on changes within neocortex similar to what is thought to occur in perceptual priming. The deficit in the probabilistic classification task indicates that impaired nondeclarative learning in patients with $\mathrm{HD}$ occurs not only in motor tasks but also in nondeclarative learning tasks that have no motor component.
\end{abstract}

Huntington's disease (HD) is an inherited progressive neurological disorder that is characterized by involuntary, choreiform movements, affective disturbance, and progressive cognitive and functional declinc. The primary neuropathology is loss of cells in the caudate nucleus and the putamen (Vonsattel et al., 1985), although there is eventually more widespread cell loss (Bruyn, Bots, \& Dom, 1979). The pattern of cognitive deficits exhibited by patients with HD is complementary in some respects to the cognitive deficits exhibited by amnesic patients (Butters, Wolfe, Martone, Granholm, \& Cermak, 1985). Amnesic patients have severely impaired declarative (or explicit) memory (Mayes, 1988; Squire, 1987). For example, they fail conventional recall and recognition tests concerning information about facts and cvents. They also perform as well as normal subjects on a variety of nondeclarative (or implicit) memory tasks (for reviews, see Schacter,

Barbara J. Knowlton, Department of Psychology, University of California, Los Angeles; Larry R. Squire, Research Service, Veterans Affairs Medical Center, San Diego, California, and Department of Psychiatry and Department of Neurosciences, University of California, San Diego; Jane S. Paulsen and Nelson Butters, Psychology Services, Veterans Affairs Medical Center, San Diego, California, and Department of Psychiatry, University of California, San Diego; Neal R. Swerdlow, Department of Psychiatry, University of California, San Diego; Michael Swenson, Department of Neurosciences, University of California, San Diego.

Nelson Butters died on November 18, 1995.

This research was supported by the Medical Research Service of the Department of Veterans Affairs, the National Institute of Mental Health, the IIuntington's Disease Society of America, and the Foundation for the Care and Cure of Huntington's Disease.

We gratefully acknowledge Nicole Champagne, Shannon Johnson, Brent Kronenberg, and Joyce Zouzounis for research assistance.

Correspondence concerning this article should be addressed to Larry R. Squire, Psychiatry Service (116A), Veterans Affairs Medical Center, 3350 La Jolla Village Drive, San Diego, California 92161. Electronic mail may be sent via Internet to lsquire@ucsd.edu.
Chiu, \& Ochsner, 1993; Squire, Knowlton \& Musen, 1993). In contrast, patients with HD typically exhibit less severe declarative memory deficits than amnesic patients do, but they are impaired on a number of tasks of nondeclarative memory. For example, they are impaired in rotor-pursuit perceptuomotor learning (Hcindel, Butters, \& Salmon, 1988) and in learning to read mirror-reversed text (Martone, Butters, Payne, Becker, \& Sax, 1984), and they exhibit impaired adaptation-level effects for weight judgments (Heindel, Salmon, \& Butters, 1991) and impaired prism adaptation (Paulsen, Butters, Salmon, Heindel, \& Swenson, 1993). Patients with HD also have difficulty acquiring the repeated sequence in a serial reaction time task (Knopman \& Nissen, 1991; Willingham \& Koroshetz, 1993). In this task, patients rapidly press keys on a computer keyboard that correspond to the spatial locations of four cues that appear sequentially on a screen above the keys. Unbeknownst to the patients, the cues appear in a repeating 10 -item sequence. Learning is demonstrated by a gradually decreasing reaction time across training trials and by an abrupt increase in reaction time when the repeating sequence is switched to a random sequence.

Although patients with HD exhibit deficits in many tasks of nondeclarative memory, they exhibit normal perceptual priming as do amnesic patients (Cave \& Squire, 1992; Bylsma, Rebok, \& Brandt, 1991; Graf, Squire, \& Mandler, 1984; Hamann, Squirc, \& Schacter, 1995; Heindel, Salmon, \& Butters, 1990; Schacter, Cooper, Tharan, \& Rubens, 1991; Shimamura, Salmon, Squire, \& Butters, 1987). For examplc, in one study, patients with HD and control subjects exhibited the same advantage in identifying previously presented pictures over nonstudied pictures, when the pictures were presented in degraded form (Butters, Heindel, \& Salmon, 1990). Bccause such perceptual priming is thought to depend on sensory cortical areas (Squire ct al., 1992; Tulving \& Schacter, 1990), it is not surprising that it is unaffected in both HD and amnesia. Sensory cortices are spared in amnesia and relativcly intact in 
HD. The results from priming studies demonstratc that HD does not impair all forms of nondeclarative memory.

One interpretation of the nondeclarative learning deficit in $\mathrm{HD}$ is that it is related to impaired formation of motor or visuomotor programs (Heindel et al., 1991) or motor sequencing (Willingham \& Koroshetz, 1993). Virtually all the examples of nondeclarative learning demonstrated to be deficient in patients with HD have an overt motor component (pursuit rotor learning and serial reaction time learning), or require changes in motor programs to occur in response to perceptual information (prism adaptation, weight judgments, and mirror reading). This deficit does not seem to occur for all motor learning tasks because patients with HD have been shown to acquire a stimulus-response mapping normally (Willingham \& Koroshetz, 1993; Willingham, Koroshetz, \& Peterson, 1996). Other evidence also suggests that the nondeclarative learning deficit in HD may not be limited to motor learning. For example, a subgroup of patients with HD were impaired in the learning of a cognitive skill (solving a problem similar to the Tower of Hanoi puzzle), which has no obvious perceptuomotor component (Saint-Cyr, Taylor, \& Lang, 1988). In addition, studies of experimental animals with caudate nucleus lesions have demonstrated impaired performance in some memory tasks that do not involve learning motor skills. In these tasks, which have been described as tasks of habit Icarning, animals Icarn across trials to gradually associatc stimuli and responses to obtain reinforcement, such as in win-stay maze learning or pattern discrimination learning (Divac, Rosvold, \& Swarcbart, 1967; McDonald \& White, 1993; Mishkin, Malamut, \& Bachevalier, 1984; Mishkin \& Petri, 1984; Packard, Hirsh, \& White, 1989). These results suggest that the caudate nucleus plays a role in some types of habit learning, even when motor skill learning is not required, and the results raise the possibility that the nondeclarative learning deficit in $\mathrm{HD}$ is not limited to learning motor programs (Salmon \& Butters, 1995).

A new body of work involving amnesic patients has identificd other kinds of nonmotor learning that are nondeclarative and independent of the limbic and diencephalic brain structures damaged in amnesia (see Knowlton, 1996 for a review). In these tasks, individuals gradually acquire knowledge of a category after seeing several exemplars of the category. In one paradigm, artificial grammar learning (Reber, 1989), individuals learn to classify novel letter strings according to a set of complex rules that define category membership after having studied examples of the grammatical category. In this paradigm, as in other tasks of nondeclarative learning, individuals are not necessarily aware of the information they have lcarned. Rather, learning is expressed by above-chance performance on the classification task. Amnesic patients perform normally on artificial grammar leaming and on other category learning tasks (Knowlton, Ramus, \& Squire, 1992; Knowlton \& Squire, 1993; Knowlton, Squire, \& Gluck, 1994; Squire \& Knowlton, 1995).

Category learning describes a broad range of abilities that could depend on different underlying mechanisms. Some category-learning tasks share similarities with habit learning in that learning appears to proceed gradually and incrementally across trials. To abstract knowledge about the nature of a category, individuals must acquire information about the commonalities among training items across a number of trials. It is thus possible that the basal ganglia are involved in some types of category learning. Alternatively, category learning could depend on other brain systems important for nondeclarative learning, such as the neocortex. In our study, we examined the performance of patients with HD on two different nondeclarative tasks of category learning, a probabilistic classification task similar to habit learning and an artificial grammar learning task.

\section{Experiment 1}

One difficulty with applying the concept of habit learning to neuropsychological studies is that humans undoubtedly use declarative memory strategies to solve many of the tasks that are learned as habits by experimental animals. For example, learning that a particular cue signals reward can be learned explicitly in a single trial by a human and would therefore depend on the medial temporal lobe memory system that is damaged in amnesia (Squire, Zola-Morgan, \& Chen, 1988). In Experiment 1, we examined the performance of patients with HD on a probabilistic classification task (the weather prediction task). In this task, the probabilistic nature of the cueoutcome associations requires that learning occur across trials. Information about a single trial is not reliable and therefore not as important as information cumulated across many trials. In this respect, probabilistic classification learning is similar to the type of incremental learning of habits that is impaired by lesions of the caudate nucleus in experimental animals. If probabilistic classification learning is analogous to habit learning, then it may also depend on the integrity of the basal ganglia in humans and thus should thus be impaired in patients with HD.

\section{Method}

\section{Participants}

Patients with $H D$. Thirteen patients ( 7 women and 6 men) with HD participated. They averaged 48.3 years of age (range $=33-61$ ) and 13.3 years of education (range $=12-16$ ). The patients were diagnosed by a senior staff neurologist on the basis of a positive family history for the disease and the presence of involuntary choreiform movements. Functional capacity was assessed using the Shoulson and Fahn scale, which rates the level of disability from 1 (minimal) to 5 (severe; Shoulson \& Fahn, 1979). The mean rating was 3.0 for the 13 patients $(2, n=5 ; 3, n=4 ; 4, n=3 ; 5, n=1)$. The mean score on the Dementia Rating scale (Mattis, 1976) was 131.4 (maximum possible $=144$; range $=124-143$ ). All patients were considered psychiatrically stable at the time of testing. Five patients were taking antipsychotic medication at the time of testing (Haldol or Loxitane), 5 patients were taking antidepressant medication (Elavil, Prozac, Trazodone, or Zoloft), and 2 patients were taking anxiolytic medication (Klonopin).

Controls The 12 controls ( 9 women and 3 men) were employees or volunteers at the University of California, San Diego, or the San Diego Veterans Affairs Medical Center. They were matched to the patients with $\mathrm{HD}$ in terms of age and years of education (mean age $=48.8$ years, range $=30-68$; mean education $=15.1$ years, range $=12-22$ ). 


\section{Materials}

The test of probabilistic classification learning was identical to the weather prediction task used in a previous study of amnesic patients (Knowlton, et al., 1994). The test was presented using a Macintosh PowerBook computer. Figure 1 shows the layout of the computer screen at the beginning of the task. The task required participants to learn which of two outcomes (rain or sunshine) will occur on each trial based on the combination of four cues that appears. The four cues were pictures of cards bearing geometric shapes (circles, diamonds, squares, and triangles). One, two, or three cues appeared on each trial, and the two outcomes occurred equally often. Thus, there were 14 possible cue patterns. The sequence of cue combinations that appeared on each trial was randomized for each participant, with the constraint that the same cue combination could not appear twice in succession and each outcome occurred no more than five times in a row.

Each cue was associated with one of the two weather outcomes with a fixed probability. Across all 14 combinations of cues, Cue 1 was associated $75 \%$ of the time with Outcome 1 and $25 \%$ of the time with Outcome 2; Cue 2 was associated $56 \%$ of the time with Outcome 1 and $44 \%$ of the time with Outcome 2; Cue 3 was associated $44 \%$ of the time with Outcome 1 and $56 \%$ of the time with Outcome 2; and Cue 4 was associated $25 \%$ of the time with Outcome 1 and $75 \%$ of the time with Outcome 2. For each participant, each of the four cues was equally likely to appear as Cue $1,2,3$, or 4 . There were 4 ! or 24 ways in which the cues could be assigned their association strength. Table 1 lists the frequency of each combination of cues and the probability of Outcome 1 given the appearance of each combination of cues.

\section{Procedure}

Participants were told that in the task they would pretend to be a weather forecaster. They were instructed that they would be seeing one to three cues on each trial, and their task would be to decide if the cues predicted sunshine or rain. They were told that at first they would be guessing but that they would gradually become better at deciding which cues predicted sunshine and rain. At the start of a trial, the cues appeared on the computer screen for $5 \mathrm{~s}$. The participant indicated his or her choice by pressing either the key labeled with a sun icon or the

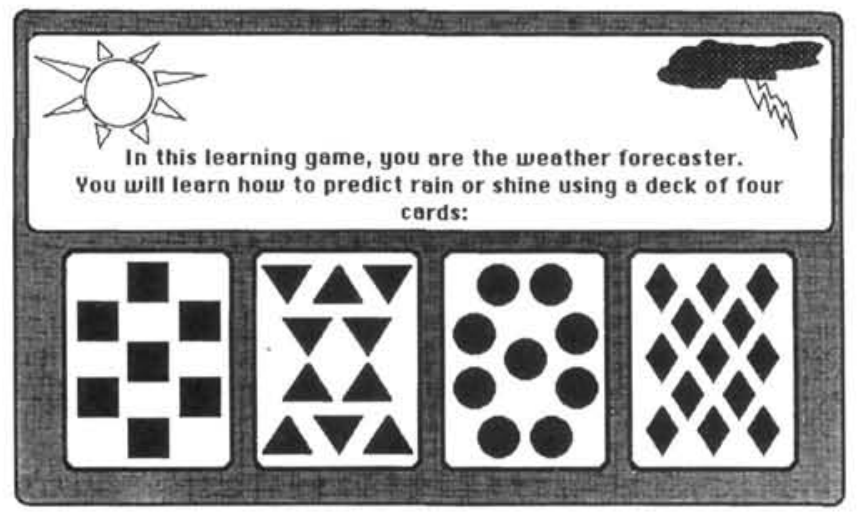

Figure 1. The appearance of the screen at the beginning of the probabilistic classification task. The four cues are shown, along with the sun and rain icons. One of these icons appeared above the cues after the response on each trial to indicate which answer was correct. From "Dissociable Properties of Memory Systems: Differences in the Flexibility of Declarative and Nondeclarative Knowledge," by Paul J. Reber, Barbara J. Knowlton, and Larry R. Squire, 1996, Behavioral Neuroscience, 110, p. 864. Copyright 1996 by the American Psychological Association.
Table 1

Probability Structure of the Task

\begin{tabular}{lccccccc}
\hline & \multicolumn{5}{c}{ Cue } & & \\
\cline { 2 - 5 } Cue pattern & 1 & 2 & 3 & 4 & $P$ (cue combination) & $P$ (outcome) \\
\hline 1 & 0 & 0 & 0 & 1 & .133 & .150 \\
2 & 0 & 0 & 1 & 0 & .087 & .385 \\
3 & 0 & 0 & 1 & 1 & .080 & .083 \\
4 & 0 & 1 & 0 & 0 & .087 & .615 \\
5 & 0 & 1 & 0 & 1 & .067 & .200 \\
6 & 0 & 1 & 1 & 0 & .040 & .500 \\
7 & 0 & 1 & 1 & 1 & .047 & .143 \\
8 & 1 & 0 & 0 & 0 & .133 & .850 \\
9 & 1 & 0 & 0 & 1 & .067 & .500 \\
10 & 1 & 0 & 1 & 0 & .067 & .800 \\
11 & 1 & 0 & 1 & 1 & .033 & .400 \\
12 & 1 & 1 & 0 & 0 & .080 & .917 \\
13 & 1 & 1 & 0 & 1 & .033 & .600 \\
14 & 1 & 1 & 1 & 0 & .047 & .857 \\
\hline
\end{tabular}

Note. On any trial, 1 of 14 possible combinations of four cues appeared with the probability indicated above [ $P$ (cue combination)]. Each combination of cues predicted Outcome 1 (sunshine) with the probability shown above $[P$ (outcome) $]$ and predicted Outcome 2 (rain) with a probability of $1-P$.

key labeled with a rain icon on the computer keyboard. These two keys (option and shift) were on the opposite sides of the keyboard to minimize the motor coordination required to make a response. If the response was correct, a high-pitched tone sounded, a smiling face appeared at the right of the screen, and a vertical scoring bar at the right of the screen, initially set at 600 , incremented 1 point. If the response was incorrect, a low-pitched tone sounded, a frowning face appeared at the right side of the screen, and the vertical bar at the right of the screen decremented by 1 point. Then, the icon (sun or rain) corresponding to the correct answer appeared on the screen above the cues for $2 \mathrm{~s}$. After a 0.5 -s intertrial interval, the next set of cues appeared. If no response was made within $3 \mathrm{~s}$, a prompt appeared on the screen asking for a response. After $5 \mathrm{~s}$ without a response, the trial was terminated, the low tone sounded, and the correct answer appeared above the cues for $2 \mathrm{~s}$ (these missed trials were not scored, and they accounted for an average of only 3.1 of 150 trials). Participants were allowed a short break $(<1 \mathrm{~min})$ after 50 and 100 trials. After a total of 150 trials were completed, they were administered an eight-item, four-alternative multiple-choice questionnaire that asked about the nature of the cues and feedback, the layout of the screen, and the testing procedure.

\section{Data Analysis}

A response was considered to be correct on a particular trial if the outcome selected was the outcome more strongly associated with the cue combination that appeared on that trial. Because of the probabilistic nature of the task, a cue combination was sometimes followed by the less strongly associated outcome. Thus, a response could be scored as correct on a particular trial, even though the feedback indicated that the response was incorrect. In this way, the percentage correct score reflected how well participants learned the cue-outcome associations. Because the two outcomes occurred equally often, chance performance was $50 \%$ correct. The data were not analyzed for trials on which the two outcomes were equally associated with the cue combination and on which there was therefore no correct answer (Combinations 6 and 9; see Table 1). These trials composed $10.7 \%$ of all the trials. For the first 50 trials, the data were analyzed in blocks of 10 trials, and the remainder of the trials were analyzed in blocks of 50 trials. 


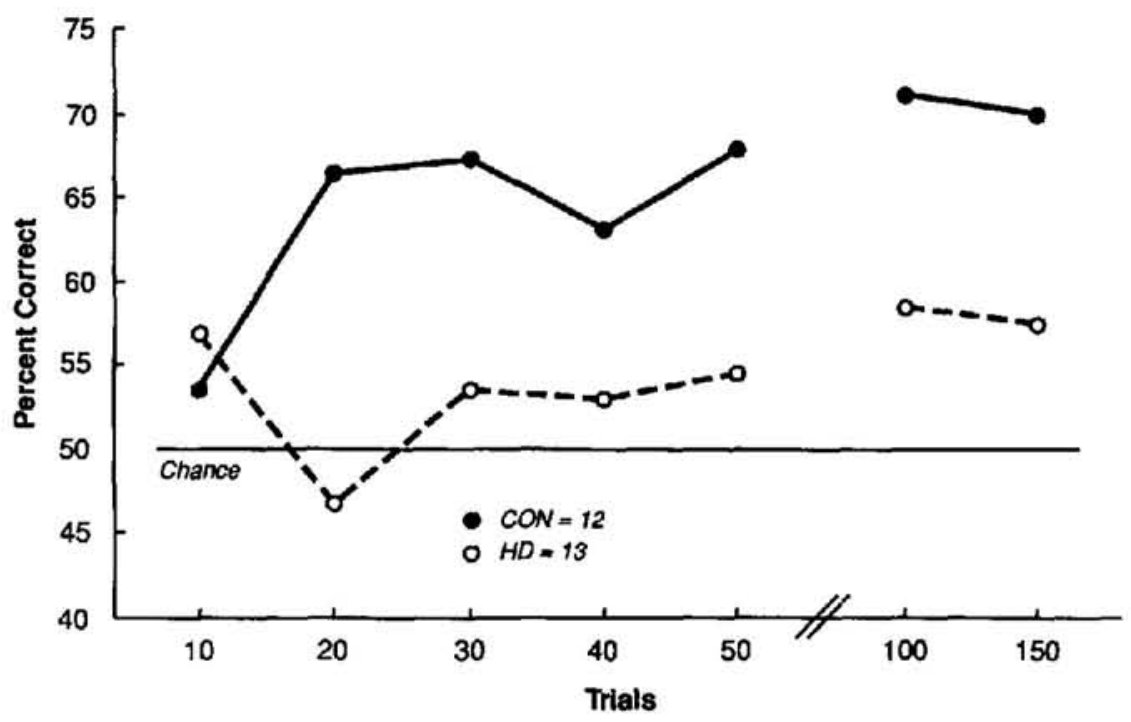

Figure 2. The performance of controls (CON) and the patients with Huntington's disease (HD) on the probabilistic classification task. The data are presented in blocks of 10 trials for the first 50 trials, and in blocks of 50 trials for trials $51-150$.

\section{Results}

Figure 2 shows the learning curve for the controls (CON) and the patients with HD. During the first 50 trials of training, the patients with HD were impaired relative to controls. An analysis of variance (ANOVA) showed a trend for a main effect of group, $F(1,23)=3.79, p<.07$, and a significant linear component interaction, $F(1,23)=4.56, p<.05)$. Whereas the CON group improved their performance during the first 50 trials, exhibiting a significant linear trend, $F(1,11)=$ $7.63, p<.05$, the patients with HD exhibited no linear trend across the first 50 trials $(F<1)$. In addition, unlike the CON group, the patients with $\mathrm{HD}$ performed at chance levels during the fifth block of 10 trials: difference from chance for CON, $t(11)=6.03, p<.01$; for HD, $t(12)=1.04, p>.20$. Performance of the patients with HD on the fifth block of trials was unrelated to the severity of their chorea, as measured by the Unified Huntington's Disease Rating scale (Chorea Severity subscale; $r=.13 p>.60$; Huntington Study Group, 1996).

During the final two blocks of 50 training trials, the CON group continued to perform better than the patients with HD, Group $\times$ Trial Block ANOVA; $F(1,23)=5.96, p<.05$. Even in the final block of 50 trials, the patients with HD performed at chance levels [difference from chance for patients with HD, $t(12)=1.98, p>.05$; for CON group, $t(11)=5.50 ; p<.01]$. Performance of the patients with HD on the final block of trials was unrelated to the severity of their chorea $(r=.16$, $p>.50$ ).

On the task of declarative memory, the patients with $\mathrm{HD}$ scored more poorly than the CON group, $(t(23)=3.84, p<$ .01 ; see Figure 3).

\section{Discussion}

In the probabilistic classification task, patients with $\mathrm{HD}$ exhibited a severe impairment in acquiring the associations between the cues and the outcomes. Both groups began at essentially chance levels (i.e., near $50 \%$ correct). The controls improved their performance during training, eventually achieving a level of about $70 \%$ correct. The patients with HD, however, exhibited no demonstrable learning across 150 trials of training. The impaired performance of the patients with $\mathrm{HD}$ contrasts sharply with the normal performance of amnesic patients during the first 50 trials of this task (Knowlton et al., 1994). Specifically, amnesic patients achieved a level of nearly $70 \%$ correct. The finding that amnesic patients can perform

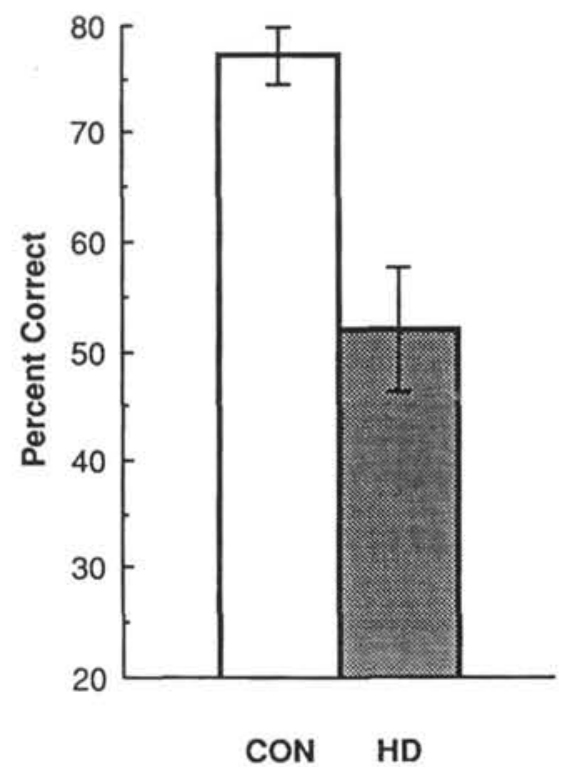

Figure 3. Performance of the two groups on the declarative memory questionnaire. Brackets show standard errors of the mean. $\mathrm{CON}=$ control group, $n=12$; HD = patients with Huntington's disease. $n=13$. 
normally on this task demonstrates that the brain regions in the medial temporal lobe and diencephalon that are important for declarative memory do not contribute to performance during the early phase of probabilistic classification learning. Our results suggest that the brain structures damaged in HD, most notably the caudate nuclcus and the putamen, are involved in probabilistic classification learning.

The present results support the idea that the probabilistic classification task is similar to habit-learning tasks that have been studied using experimental animals. As with habit learning, in the probabilistic classification task individuals acquire associations across trials. In experimental animals, performance on habit-learning tasks is spared by lesions of the hippocampal system but impaired by lesions of the caudate nucleus. Our results suggest that a habit-learning system with a neostriatal substrate is present in humans as well.

In previous studics of HD, there has been an emphasis on the loop between the neostriatum and the frontal cortex (c.g., Saint-Cyr et al., 1988). Deficits in HD have been viewed as emerging from dysfunction in this loop rather than dysfunction in the neostriatum. In the present study, frontal lobe dysfunction may have contributed to the impaired performance of the patients with HD on this task. However, the roles of the neostriatum and frontal lobes can be dissociated (Owen, Roberts, Hodges, Summers, Polkey, \& Robbins, 1993). Moreover, in a recent study, nondemented patients with Parkinson's disease failed to improve at the probabilistic classification task during 50 trials, whereas patients with frontal lobe lesions performed satisfactorily (Knowiton, Mangels, \& Squire, in press). Finally the similarity between the probabilistic classification task and caudate-dependent habit-learning tasks in experimental animals also favors a ncostriatal locus for this type of learning.

In contrast to certain studies with experimental animals (McDonald \& White, 1993; Packard et al., 1989), a complete double dissociation with the findings from amnesic patients was not achieved in the present experiment. That is, the patients with HD werc impaired in classification learning but did not perform normally on the questionnairc. Impaired performance on declarative memory tests typically accompanies HD (Martone, et al., 1984; Massman, Delis, Butters, Levin, \& Salmon, 1990; Pillon, Deweer, Agid, \& Dubois, 1993) and presumably reflects the fact that HD involves brain structures other than the neostriatum, including medial temporal and frontal areas important for declarative memory (Braak \& Braak, 1992; Cudkowicz \& Kowall, 1990; Sotrel et al., 1991; Spargo, Everall, \& Lantos, 1993). The multiple-choice questionnairc asked for recall of elements from the testing episode, and a deficit in patients with HD would therefore be expected if there is medial temporal lobe and frontal patholngy. However, it is worth noting that the patients with HD exhibited a trend toward better performance on the questionnaire, compared with the 8 amnesic patients in a previous study [Knowlton et al., $1994 ; 51.9 \%$ vs. $37.5 \%$ correct, $t(19)=1.75, p<.1]$. Thus, even though the patients with HD exhibited marginally better declarative memory than did amnesic patients, the amnesic patients performed normally on the classification task, whereas the patients with HD were unable to exhibit any learning in the classification task.

\section{Experiment 2}

The results of Experiment 1 add to the evidence that there arc deficits in nondeclarative learning in $\mathrm{HD}$, and they establish that these deficits extend beyond tasks that depend on motor learning. At the same time, it is clear that not all types of implicit memory are impaired in HD (e.g., perceptual priming). This finding probably reflects differences in the neural substrates underlying priming and other nondeclarative learning tasks. Data from functional imaging studies suggest that perceptual priming arises as a result of increased efficiency of processing in the posterior cerebral cortex (Buckner, et al., 1995; Schacter, Alpert, Savage, Rauch, \& Albert, 1996; Squire et al., 1992). This finding is consistent with the normal performance of patients with HD on perceptual priming tasks, as HD primarily affects subcortical structures. In contrast, the gradual accrual of associative strength that occurs in the probabilistic classification task may ordinarily depend on the basal ganglia structures damaged in HD.

The question naturally arises whether other types of category learning also depend on basal ganglia structures. In the artificial grammar learning task, individuals see examples of letter strings that belong to a grammatical category, which is defined by a set of rules that allow only certain letters to follow other letters. After viewing a set of grammatical letter strings, individuals are able to classify new letter strings according to these rules (Mathews ct al., 1989; Reber, 1976; 1989). As in the case of probabilistic classification, amnesic patients exhibit normal performance in this paradigm (Knowlton et al., 1992; Knowlton \& Squire, 1994). One possibility is that artificial grammar learning is similar to probabilistic classification learning in that information about the category (e.g., the rules or the frequencies of permissible letter combinations) must be acquired gradually across many trials. Another possibility is that artificial grammar learning is more similar to priming in that it depends on brain systems other than the basal ganglia.

In Experiment 2, we cxamined whether patients with HD can acquire information about an artificial grammar. If patients with HD are impaired, it would suggest that this task shares some aspects of the probabilistic classification task and could be potentially viewed as a type of habit learning. However, if they perform this task normally, it would suggest that artificial grammar learning does not depend on the basal ganglia and is thus distinct from neostriatal-dependent habit learning.

\section{Method}

\section{Participants}

Parients with HD. Ten patients with Huntington's disease (6 men and 4 women) participated in this study. Eight had participated in Experiment 1. Of the 2 other patients, 1 patient was taking antidepressant medication at the time of testing (Elavil). All patients were considered psychiatrically stable at the time of testing. The 10 patients averaged 44.0 years of age (range $=26-61$ ) and 13.3 years of education (range $=12-16$ ). The mean rating for the 10 patients on the Shoulson and Fahn scale (Shoulson \& Fahn, 1979) was 3.0 (range =1-5). The mean score on the Dementia Rating scale was 129.2 (range $=124$ 143). 
Controls. The 12 control subjects ( 8 women and 4 men) were employees or volunteers at the University of California, San Diego, or the San Diego Veterans Affairs Medical Center. They averaged 41.8 years of age (range $=25-66$ ), and 13.8 years of education (range $=10$ 16 years).

\section{Materials}

The materials were identical to those used by Knowlton et al. (1992). We used two finite-state rule systems, known as artificial grammars (Figure 4), to generate the training and test stimuli. Letter strings were generated from each rule system by starting at the "IN" arrow and traversing the diagram along the arrows until the "OUT" arrow was reached. Forty-six grammatical letter strings of two to six letters in length were generated from each artificial grammar. Twenty-three of these letter strings served as training items, and the other 23 served as target items on the test. In addition, 46 different letter strings were generated such that a letter violating the grammatical rules was substituted at one position in an otherwise grammatical letter string. The rule violation occurred nearly equally often in the first, second, middle, second to last, and last positions within the nongrammatical letter strings. Twenty-three of these nongrammatical letter strings were used as distractors on the classification task, and 23 were used as distractors on a recognition test for the training items. The letter strings were printed in capital letters approximately $1.5 \mathrm{~cm}$ in height on index cards.

\section{Procedure}

Classification task. One half of the participants were trained with Grammar A, and the other half were trained with Grammar B. To begin, the 23 training items were presented one at a time for $9 \mathrm{~s}$ each, and then a second time for a total of 46 presentations. Immediately after each item was presented, participants attempted to reproduce it using a pencil and slip of paper. If they were unsuccessful, the slip of paper was removed and the same item was presented again for $9 \mathrm{~s}$ and the opportunity was given to reproduce it. If they were still unsuccessful, the same procedure was repeated a third time before moving on to the next item. We used a presentation time of $9 \mathrm{~s}$ because preliminary work indicated that patients with HD had difficulty reproducing items that were presented for the shorter duration used with amnesic patients $(3 \mathrm{~s})$. With a 9 -s presentation duration, the patients were able to reproduce $79.2 \%$ of the items correctly after the first exposure, and they were able to complete $96.9 \%$ of the items within three attempts. The control group completed $94.9 \%$ of the items after the first exposure and $99.6 \%$ of the items within three attempts. Five min after the grammatical items were presented, participants were informed for the first time that the letter strings they had just seen were formed according to a set of complex rules. They were told that they would next see a new set of items, and that their task was to decide which items followed the rules and which did not. Participants were instructed as follows:

The rules are very complex, so you may not be able to figure them out. You may want to go on a 'gut feeling' as to whether the item follows the rules as in the first set of items.

Participants were then shown 46 new letter strings one at a time (23 new grammatical strings intermixed with 23 nongrammatical distractors), which they classified as correct or incorrect according to whether they thought the letter string conformed to the grammatical rules.

Recognition task. A yes-no recognition task was given on a later testing session (for patients with $\mathrm{HD}$, a mean of 3.5 months later; for the control group, a mean of 10.4 days later). Each participant was tested using the materials from the grammar ( $A$ or $B$ ) that had not been used for that participant for the earlier classification test. The 23 training letter strings were presented exactly as in the classification task. After a 5-min delay, participants were told that they would see more items, and their task was to decide for each whether it had been presented a few minutes earlier or whether it was a new item. The $\mathbf{4 6}$ test items consisted of the 23 training items intermixed with 23 nongrammatical distractor items.

\section{Results}

\section{Classification Task}

During training, the patients with HD required a mean of 1.19 presentations before an item could be correctly reproduced (with $3.1 \%$ of the items never correctly completed), whereas the controls required a mean of only 1.03 presentations (with $0.4 \%$ of the items never correctly completed). The group difference in the number of presentations was significant, $t(20)=3.52, p<.01$.

Patients with HD and the control group performed significantly above chance $(50 \%)$ on the classification task $(t \mathrm{~s}>3.4$, $p s<.01$ ). The patients with HD scored $60.2 \pm 3.0 \%$ correct, and the control group scored $63.2 \pm 2.5 \%$ correct (see Figure $5)$. These two scores did not differ significantly from each other, $t(20)=.77, p>.10$. In addition, an item analysis carried out on the test items from the two grammars showed that the patients and the control group tended to endorse the same items as grammatical (for Grammar A, $r=.30$ ); for Grammar $\mathrm{B}, \mathrm{r}=.28, p \mathrm{~s}<.01)$.

Although the patients with HD requircd significantly more presentations to complete items during training than control group, the number of presentations did not correlate with eventual performance on the classification task $(r=.11$, $p>.10)$.
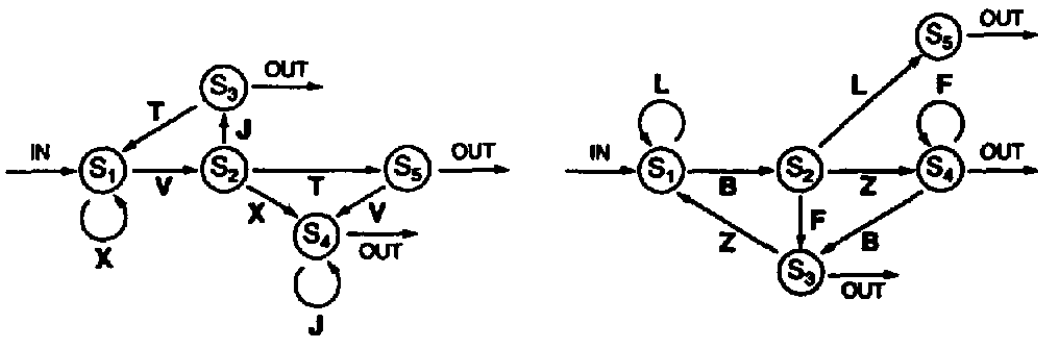

Figure 4. Two artificial grammars used to generate grammatical letter strings for Experiment 2. 


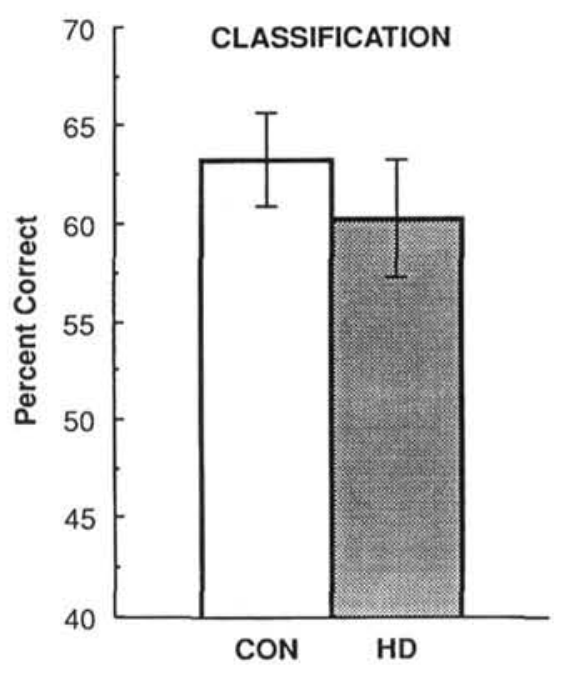

Figure 5. Performance of the two groups on the classification task. $\mathrm{CON}=$ control group, $n=12 ; \mathrm{HD}=$ patients with Huntington's disease, $n=10$. Brackets show standard errors of the mean.

\section{Recognition Task}

Both groups exhibited above-chance recognition performance $(t \mathrm{~s}>4.5, p \mathrm{~s}<.01)$, but there was a trend for the patients with $\mathrm{HD}$ to perform more poorly than the controls. The patients with $\mathrm{HD}$ scored $65.4 \pm 3.4 \%$ correct, whereas the control group scored $73.3 \pm 2.9 \%$ correct, $t(20)=1.76, p=$ .09 ; see Figure 6).

\section{Discussion}

In Experiment 2, patients with HD learned to discriminate grammatical from nongrammatical letter strings as well as the control group. These results indicate that artificial grammar learning does not depend on the brain structures damaged in

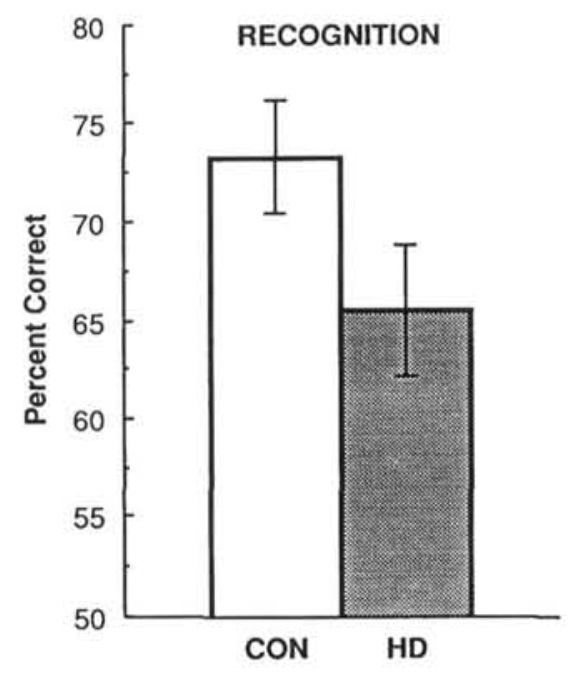

Figure 6. Performance of the two groups on the recognition task for training letter strings. $\mathrm{CON}=$ controls, $n=12 ; \mathrm{HD}=$ patients with Huntington's disease, $n=10$. Brackets show standard errors of the mean.
HD. Because amnesic patients also perform normally in the artificial grammar learning task (Knowlton et al., 1992; Knowlton \& Squirc, 1994), it appears that this type of learning is independent of both the medial temporal lobe and diencephalic structures damaged in amnesia as well as the basal ganglia. The question arises as to what brain structures are essential for this type of learning. To address this issue, one must first consider what kind of information is acquired when an individual studies a set of grammatical letter strings. Recent research suggests that more than one type of information is acquired in this task. Individuals appear to learn some abstract information about the grammatical rules as well as more specific information tied to the particular letter strings presented during training. This conclusion comes from data showing that ncurologically intact individuals, as well as amnesic patients are able to transfer their knowledge of an artificial grammar to letter strings formed from a new set of letters (Gomez \& Schwaneveldt, 1994; Knowlton \& Squire, 1996), and that individuals can cven transfer their knowledge across sensory modalities and stimulus types (e.g., from tone sequences to letter sequences; Altmann, Dienes, \& Goode, 1995). To exhibit such transfer, individuals must have acquired some abstract information about the underlying grammatical rules. At the same time, it is also truc that individuals consistently perform better when the same set of letters is used to construct study items and test items, which suggests that important information is also acquired that is specific to the training items. One kind of exemplar-specific knowledge that individuals apparently use to make judgments of grammaticality is the frequency with which different letter bigrams and trigrams (chunks) occur in the training items. Test letter strings containing chunks that were repeated frequently during training are considered to have a high "chunk strength," and such test itcms are correspondingly endorsed more frequently than test items containing chunks that were repeated less frequently (Knowiton \& Squire, 1994; Servan-Schreiber \& Anderson, 1990).

The influence of chunk strength on grammaticality judgments suggests some similarities between artificial grammar learning and the phenomenon of perceptual priming. For example, test letter strings containing chunks that were repeated frequently during training should be processed more fluently than items containing chunks that were repeated less frequently. Increased perceptual fluency might then influence grammaticality judgments, just as perceptual fluency has been shown to influence judgments in the famous-names task. In this task, participants are presented with a series of fictitious names, and then after a delay they judge a set of names as to whether or not each name is famous or nonfamous. Nonfamous names that were presented previously are more likely to be judged famous than new nonfamous names, suggesting that the increased fluency associated with the prior presentation of the names influenced judgments at test (Jacoby, Woloshyn, \& Kelley, 1989; Neely \& Payne, 1983; Squire \& McKee, 1992). Preexposure to stimuli has also been shown to influence liking judgments, which may similarly result from perceptual fluency (Bonnano \& Stillings, 1986; Kunst-Wilson \& Zajonc, 1980). There is also evidence that training with grammatical stimuli can result in enhanced perceptual fluency 
for new grammatical letter strings. Buchner (1994) showed individuals a series of grammatical letter strings and then tested their ability to perceive new letter strings in a perceptual identification task. Participants were able to perceive grammatical items better than nongrammatical items.

The normal performance of patients with HD in the artificial grammar task is consistent with the idea that performance on this task is derived, at least in part, from perceptual priming. This idea is supported by the fact that these patients exhibit normal perceptual priming (Butters et al., 1990; Bylsma et al., 1991; Heindel ct al., 1990). It is not clear whether patients with HD are achieving normal performance on the artificial grammar task by using perceptual fluency alone, or if they additionally acquire more abstract information, as the control group and amnesic patients seem to do. In the present study, the nonsignificant numerical difference $(3 \%)$ between the HD and control groups may have been duc to an impairment in the ability of patients with HD to acquire rule-based information. The test materials in the present experiment do not allow an examination of differences in the type of information learned by the two groups in the task because the test items that obeyed the grammatical rules also tended to have higher chunk strength than nongrammatical test items. That is, the chunk strength of the test items and their rulc adherence were confounded. If the learning of abstract, rule-based information in this task does depend on the basal ganglia, then patients with HD should exhibit deficits on artificial grammar tasks when the grammatical test items are not associated with enhanced perceptual fluency, such as when testing is carried out with test items formed from a different letter sct than the one used during training.

Despite the good performance of patients with HD on the classification test, they were marginally impaired relative to the control group on a recognition task for the study items. This dissociation between marginally impaired recognition and intact classification performance exhibited by the patients with HD in Experiment 2 is demonstrated more clearly in amnesic patients who exhibit normal classification performance despite severely impaired recognition. The results from amnesic patients and patients with HD support the idea that artificial grammar learning is independent of the brain system that contributes to recognition memory.

\section{General Discussion}

In the present study, patients with HD exhibited a deficit in one nondeclarative learning task (probabilistic classification learning, Experiment 1), but performed well in a second nondeclarative learning task (artificial grammar learning, Experiment 2). These two tasks appear to depend on different neural systems. Impaired performance of patients with HD on the probabilistic classification task suggests that the formation of cue-outcome associations in this task depends on brain structures damaged in HD, notably the caudate nucleus and the putamen (Vonsattel et al., 1985). In contrast, learning to make classification judgments in the artificial grammar task does not appear to rely on these structures. The results of the two experiments together underscore the idea that nondeclarative memory is composed of different abilities that depend on different brain systems (see Squire, Knowlton, \& Musen, 1993).

The poor performance of the patients with HD in Experiment 1 on both the classification task and the multiple-choice questionnaire raises the possibility that the patients with HD are simply impaired on all difficult learning tasks. However, in Experiment 2, in which most of the same patients participated, performance was normal on the artificial grammar learning task. This task is demanding and complex, and performance of both groups was far from a ceiling level. Thus, it appears that there is some specificity to the learning deficit in HD.

In both tasks described in this study, individuals acquired the ability to categorize stimuli. In this sense, both tasks involve category learning. However, the dissociation obtained by the patients with HD demonstrates that the processing demands of the two tasks must differ. Underlying the probabilistic classification task is the gradual and incremental learning of associations between cues and outcomes. Because of the probabilistic nature of the task, acquisition of the cuc-outcome associations must take place over numerous trials. The formation of such associations or habits, independent of awareness and explicit memory, may be an important cognitive function of the basal ganglia (Knowlton et al., in press). This view has received support from studies of experimental animals (Mishkin, et al., 1984; Packard et al., 1989), suggesting some convergence across species in the role of the caudate nucleus in memory function. In addition, other implicit-learning deficits seen in HD may also reflect an underlying difficulty in the gradual acquisition of associations. For example, motor programming deficits could also be seen as an impairment in the association of appropriate motor responses with eliciting stimuli.

In contrast to the probabilistic classification task, artificial grammar learning does not necessarily require the formation of associations. Participants view letter strings and later classify new letter strings as to whether or not they follow the same rules as the training items. Recent work has shown that fairly specific information about letter bigram and trigram frequencies has a substantial influence on artificial grammar judgments (Dienes, Broadbent, \& Berry, 1991; Knowiton \& Squire, 1996; Perruchet \& Pactcau, 1990). Because such concrete information is important, it raises the possibility that perceptual priming contributes to grammaticality judgments. Perhaps patients with HD can exhibit normal category learning when perceptual fluency. can be used to discriminate category members from nonmembers, whereas caudatedependent processing might be necessary for the implicit acquisition of associations between features and particular category labels.

Previous work has demonstrated a number of dissociations within nondeclarative (implicit) learning, even within domains of implicit learning, such as priming (for a review, see Butters \& Salmon, 1995). For example, patients with Alzheimer's disease exhibited impaired conceptual priming (e.g., in a category-exemplar generation task), although they exhibited normal perceptual priming (e.g., in tasks of identifying briefly presented stimuli or fragmented pictures; Gabrieli et al., 1994; Kcane, Gabrieli, Fennema, Growdon, \& Corkin, 1991; Monti et al., 1995; Salmon, Shimamura, Butters, \& Smith, 1988). 
Recently, a dissociation in priming was reported that is opposite to what has been seen in patients with Alzheimer's disease. Patient M.S., who underwent a right occipitotemporal lobectomy for the treatment of severe epilepsy, exhibited impaired perceptual priming but intact conceptual priming (Gabrieli, Fleischman, Keane, Reminger, \& Morrell, 1995).

Another dissociation between types of implicit memory is exhibited by patients with cerebellar damage, who exhibit impaired eyeblink conditioning, yet perform normally on the test of probabilistic classification learning used here (I. Daum, personal communication, Fcbruary 1995; Daum et al., 1993; Lye, O'Boyle, Ramsden, \& Schady, 1988). Together, the results from these experiments suggest that the basal ganglia, visual cortex, cortical association areas, and the cerebellum all support separate kinds of implicit memory. Each of the nondeclarative memory tasks under discussion (probabilistic classification learning, perceptual and conceptual priming, artificial grammar learning, and eyeblink conditioning) can bc performed normally by patients with amnesia. Yet several different brain systems support performance on these tasks.

The results of Experiment 1 suggest that implicit memory deficits in HD are not solely impairments in motor learning per se, but that some types of implicit nonmotor learning may be affected as well. In two previous studies, patients with HD were reported to be impaired in learning implicit memory tasks with no overt motor component. In one study, patients with HD were impaired at acquiring the skill of reading mirrorreversed text (Martone et al., 1984). One difficulty with the interpretation of this finding is the fact that patients with $\mathrm{HD}$ exhibit aberrant eye movements (Petit \& Milbled, 1973), which may impair reading ability. Indeed, baseline reading ability of patients with HD was considerably slower than that of controls. In another study, patients with HD exhibited impaired learning of the Tower of Toronto puzzle, a variation of the Tower of Hanoi problem (Saint-Cyr, et al., 1988). One subgroup of patients $(n=4)$ learned the puzzle normally but exhibited impaired declarative memory for the testing episode, a second subgroup ( $n=4$ ) was impaired at learning the puzzle but exhibited normal declarative memory, a third subgroup $(n=4)$ of more severely affected patients was impaired on both measures. These data provide some evidence for cognitive skill learning deficits in HD. Yet, other data showing that learning of the Tower of Hanoi puzzle may not always be intact in amnesia (Gabrieli, Kcanc, \& Corkin, 1987; Martone et al., 1984) suggest that performance on this task depends to some extent on declarative (explicit) memory. The HD deficit on this task could have been a result of declarative learning deficits related to dementia.

It is true that in Experiment 1, motor responses indicated the choices on each trial, but learning was measured by choice accuracy, not by enhanced motor skill or facility. Thus, the impairment observed in patients with HD was in the formation of associations. The results therefore suggest that the human neostriatum is involved in some types of associative learning (also see Knowlton et al., in press). In experimental animals, lesions of the neostriatum impair performance on a number of habit-learning tasks in which the formation of associations between stimuli and responses are required. In these tasks, learning is not indicated by changes in motor responses but rather by changes in the probability or the facility with which a stimulus elicits a particular response. Examples of habitlearning tasks impaired by caudate lesions include win-stay learning on a radial arm maze, discrimination learning in a water maze, and learning a set of discriminations concurrently with 24-hr intertrial intervals (Malamut, Saunders, \& Mishkin, 1984; McDonald \& White, 1993; Packard, et al., 1989; Wang, Aigner, \& Mishkin, 1990). Performance on each of these tasks is unaffected by lesions of the hippocampal region. In contrast, other tasks that are similar in many respects, such as win-shift learning on a radial arm maze, learning the location of a hidden platform in a water maze, and delayed nonmatching to sample performance, are impaired by lesions of the hippocampal region and unimpaired by neostriatal lesions. This double dissociation must result from differences in the operation of different brain systems and in the kind of information learned in the different types of task.

Caudate-based habit learning can be differentiated from the type of lcarning dependent on the hippocampal region in that it is more gradual, leading to an incremental buildup of associations, and it is often considered to establish stimulusresponse ( $\mathrm{S}-\mathrm{R}$ ) connections, in contrast to stimulus-stimulus (S-S) connections (Hirsh, 1974; Mishkin et al., 1984). Indeed, the term habit has traditionally been closely associated with S-R learning (c.g., Hull, 1943). The probabilistic categorylcarning task of Experiment 1 is similar to habit-learning tasks in that it is independent of the hippocampal region, it appears to depend on the neostriatum, and the relevant associations are formed across multiple trials. It is less clear how learning in this task is represented, for example, as the formation of $\mathbf{S}-\mathbf{R}$ associations such as between the cues and motor responses needed to press particular keys, as associations between the cues and internal (covert) responses involved in selecting particular outcomes, or as associations that are more like S-S connections (such as associations between cues and the outcomes themselves). Indeed, it is possible that neither S-R nor S-S learning, as these terms were used in traditional learning theory, is fully appropriate to describe the operation of the neostriatal habit-learning system. Nevertheless, the connections between the neostriatum and its input and target structures are consistent with the idea that this system forms S-R connections. Information from disparate cortical regions is transmitted to the caudate nucleus and to the putamen, which in turn project to the frontal cortex via the globus pallidus and the thalamus (Alexander, DeLong, \& Strick, 1986; Kemp \& Powell, 1971). Motor regions in the frontal cortex are the primary recipient of these projections. Additional outputs of the basal ganglia to nonmotor frontal regions, including dorsolateral and orbitofrontal regions, as well as projections to area TE in the temporal lobe (Middleton \& Strick, 1996), give rise to the possibility of the formation of nonmotor associations within the cortico-striatal system.

\section{References}

Alexander, G. E., DeLong, M. R., \& Strick, P. L. (1986). Parallel organization of functionally segegated circuits linking hasal ganglia and cortex. Annual Review of Neuroscience, 9, 357-381.

Altmann, G. T. M., Dienes, Z., \& Goode, A. (1995). Modality 
independence of implicitly learned grammatical knowledge. Joumal of Experimental Psychology: Leaming, Memory, and Cognition, 2l, 899-912.

Bonnano, G. A., \& Stillings, N. A. (1986). Preference, familiarity, and recognition after repeated brief exposures to random geometric shapes. American Journal of Psychology, 99, 403-415.

Braak, H., \& Braak, E. (1992). Allocortical involvement in Huntington's disease. Neuropathology and Applied Neurobiology, 18, 539-547.

Bruyn, G. W., Bots, G., \& Dom, R. (1979). Huntington's chorea: Current neuropathological status. In T. Chase, N. Wexler, \& A. Barbeau (Eds.), Advances in neurology: Vol 23. Huntington's Disease (pp. 83-94). New York: Raven Press.

Buchner, A. (1994). Indirect effects of synthetic grammar learning in an identification task. Journal of Experimental Psychology: Leaming, Memory, and Cognition, 20, 550-566.

Buckner, R. L., Petersen, S. E., Ojemann, J. G., Miezin, F. M., Squire, L. R., \& Raichle, M. E. (1995). Functional anatomical studies of explicit and implicit memory retrieval tasks. Joumal of Neuroscience, $15,12-29$.

Butters, N., Heindel, W. C., \& Salmon, D. P. (1990). Dissociation of implicit memory in dementia: Neurological implications. Bulletin of the Psychonomic Society, 28, 359-366.

Butters, N., \& Salmon, D. P. (1995). Neurobiology of skill and habit learning. Current Opinion in Neurobiology, 5, 184-190.

Butters, N., Wolfe, J., Martone, M., Granholm, E., \& Cermak, L. S. (1985). Memory disorders associated with Huntington's disease: Verbal recall, verbal recognition, and procedural memory. Neuropsychologia, 23, 729-743.

Bylsma, F. W., Rebık, G. W., \& Brandt, J. (1991). Long-term retention of implicit learning in Huntington's disease. Neuropsychologia, 29, 1213-1221.

Cave, C. B., \& Squire, L. R. (1992). Intact and long-lasting repetition priming in amnesia. Joumal of Experimental Psychology: Leaming, Memory and Cognition, 18, 509-520.

Cudkowicz, M., \& Kowall, N. W. (1990). Degeneration of pyramidal projection neurons in Huntington's disease cortex. Annals of Neurology, 27, 200-204.

Daum, I., Schugens, M. M., Ackermann, H., Lutzenberger, W., Dichgans, J., \& Birbaumer, N. (1993). Classical conditioning after cerebellar lesions in humans. Behavioral Neuroscience, 107, 748-756.

Dienes, Z., Broadbent, D., \& Berry, D. (1991). Implicit and explicit knowledge bases in artificial grammar learning. Joumal of Experimental Psychology: Learning, Memory and Cognition, 17, 875-887.

Divac, I., Rosvold, H. E., \& Swarcbart, M. K. (1967). Behavioral effects of selective ablation of the caudate nucleus. Journal of Comparative and Physiological Psychology, 63, 184-190.

Gabrieli, J. D. E., Fleischman, D. A., Keane, M. M., Reminger, S. L., \& Morrell, F. (1995). Double dissociation between memory systems underlying explicit and implicit memory in the human brain. Psychological Science, 6, 76-82.

Gabrieli, J. D. E., Keane, M. M., \& Corkin, S. (1987). Acquisition of problem solving skills in global amnesia. Society for Neuroscience Abstracts, 13, 1455.

Gabrieli, J. D. E., Keane, M. M., Stanger, B. Z., Kjelgaard, M. M., Growdon, J. H., \& Corkin, S. (1994). Dissociations among perceptualstructural, lexical-semantic, and event-fact memory systems in amnesic, Alzheimer's, and normal subjects. Cortex, 30, 75-103.

Gomez, R., \& Schwaneveldt, R. W. (1994). What is learned from artificial grammars: Transfer tests of simple association. Joumal of Experimental Psychology: Leaming. Memony, and Cognition, 20, 396-410.

Graf, P., Squire, L. R., \& Mandler, G. (1984). The information that amnesic patients do not forget. Journal of Experimental Psychology: Learning, Memory, and Cognition, 10, 164-178.

Hamann, S. B., Squire, L. R., \& Schacter, D. L. (1995). Perceptual thresholds and priming in amnesia. Neuropsychology, 9, 3-15.
Heindel, W. C., Butters, N., \& Salmon, D. P. (1988). Impaired learning of a motor skill in patients with Huntington's disease. Behavioral Neuroscience, 102, 141-147.

Heindel, W. C., Salmon, D. P., \& Butters, N. (1990). Pictorial priming and cued recall in Alzheimer's and Huntington's disease. Brain and Cognition, 13, 282-295.

Heindel, W. C., Salmon, D. P., \& Butters, N. (1991). The biasing of weight judgments in Alzheimer's and Huntington's disease: A priming or programming phenomenon? Journal of Clinical and Experimental Neuropsychology, 13, 189-203.

Hirsh, R. (1974). The hippocampus and contextual retrieval of information from memory: A theory. Behavioral Biology, 12, 421-444.

Hull, C. L. (1943). Principles of behavior. New York: Appleton-CenturyCrofts.

Huntington Study Group. (1996). Movement Disorders, 11, 136-142.

Jacoby, L. L., Woloshyn, V., \& Kelley, C. (1989). Becoming famous without being recognized: Unconscious influences of memory produced by dividing attention. Joumal of Experimental Psychology: General, 118, 115-125.

Keane, M. M., Gabrieli, J. D. E., Fennema, A. C., Growdon, J. H., \& Corkin, S. (1991). Evidence for a dissociation between perceptual and conceptual priming in Alzheimer's disease. Behavioral Neuroscience, 105, 326-342.

Kemp, J. M., \& Powell, T. P. S. (1971). The connections of the striatum and the globus pallidus: Synthesis and speculation. Philosophical Transactions of the Royal Society of London. Series B: Biological Sciences, 262, 441-457.

Knopman, D. S., \& Nissen, M. J. (1991). Procedural learning is impaired in Huntington's disease: Evidence from the serial reaction time task. Neuropsychologia, 29, 245-254.

Knowlton, B. J. (1996). Category learning in amnesia. In T. Nakajima (Ed.), Emotion, memory, and behavior: Study of human and nonhuman primates (pp. 105-115). Tokyo: Japan Scientific Societies Press.

Knowlton, B. J., Mangels, J. A., \& Squire, L. R. (in press). A neostriatal habit learning system in humans. Science.

Knowlton, B. J., Ramus, S. J., \& Squire, L. R. (1992). Intact artificial grammar learning in amnesia: Dissociation of classification learning and explicit memory for specific instances. Psychological Science, 3, 172-179.

Knowlton, B. J., \& Squire, L. R. (1993, December 10). The learning of natural categories: Parallel memory systems for item memory and category-level knowledge. Science, 262, 1747-1749.

Knowlton, B. J., \& Squire, L. R. (1994). The information acquired during artificial grammar learning. Joumal of Experimental Psychology: Learning, Memory, \& Cognition, 20, 79-91.

Knowlton, B. J., \& Squire, L. R. (1996). Artificial grammar learning depends on implicit acquisition of both abstract and exemplarspecific information. Journal of Experimental Psychology: Learning, Memony, and Cognition, 22, 169-181.

Knowlton, B. J., Squire, L. R., \& Gluck, M. A. (1994). Probabilistic classification learning in amnesia. Leaming \& Memory, 1, 106-120.

Kunst-Wilson, W. R., \& Zajonc, R. B. (1980, February 1). Affective discrimination of stimuli that cannot be recognized. Science, 207, 557-558.

Lye, R. H., O'Boyle, D. J., Ramsden, R. T., \& Schady, W. (1988). Effects of a unilateral cerebellar lesion on the acquisition of eyeblink conditioning in man. Journal of Physiology, 403, 58.

Malmut, B. L., Saunders, R. C., \& Mishkin, M. (1984). Monkeys with combined amygdalo-hippocampal lesions succeed in object discrimination learning despite 24-hour intertrial intervals. Behavioral Neuroscience, 98, 759-769.

Martone, M., Butters, N., Payne, M. Becker, J., \& Sax, D. S. (1984). Dissociations between skill learning and verbal recognition in amnesia and dementia. Archives of Neurology, 34, 965-970.

Massman, P. J., Delis, D. C., Butters, N., Levin, B. E., \& Salmon, D. P. 
(1990). Are all subcortical demntias alike? Verbal learning and memory in Parkinson's and Huntington's disease patients. Joumal of Clinical and Experimental Neuropsychology, 12, 729-744.

Mathews, R. C., Buss, R. R., Stanley, W. B., Blanchard-Fields, F., Cho, J. R., \& Druhan, B. (1989). The role of implicit and explicit memory processes in learning from examples: A synergistic effect. Journal of Experimental Psychology: Leaming, Memory, and Cognition, 15, 10831100.

Mattis, S. (1976). Mental status examination for organic mental syndrom in the elderly patient. In L. Bellack \& T. B. Karasu (Eds.), Geriatric psychiatry (pp. 77-121). New York: Grune \& Stratton.

Mayes, A. R. (1988). Human organic memory disorders. New York: Oxford University Press.

McDonald, R. J., \& White, N. M. (1993). A triple dissociation of memory systems: Hippocampus, amygdala, and dorsal striatum. Behavioral Neuroscience, 61, 260-270.

Middleton, F. A., \& Strick, P. L. (1996). The temporal lobe is a target of output from the basal ganglia. Proceedings of the National Academy of Sciences, USA, 93, 8683-8687.

Mishkin, M., Malamut, B., \& Bachevalier, J. (1984). Memories and habits: Two neural systems. In G. Lynch, J. L. McGaugh, \& N. M. Weinberger (Eds.), Neurobiology of learning and memory (pp. 6577). New York: Guilford Press.

Mishkin, M., \& Petri, H. L. (1984). Memories and habits: Some implications for the analysis of learning and retention. In N. Butters \& L. R. Squire (Eds.), Neuropsychology of memory (pp. 287-296). New York: Guilford Press.

Monti, L. A., Gabrieli, J. D. E., Reminger, S. L., Rinaldi, J. A., Wilson, R. S., \& Fleischman, D. A. (1995). Differential effects of aging and Alzheimer's disease upon conceptual implicit and explicit memory. Neuropsychology, 10, 101-112.

Neely, J. H., \& Payne, D. G. (1983). A direct comparison of recognition failure rates for recallable names in episodic and semantic memory tests. Memory \& Cognition, 11, 161-171.

Owen, A. M., Roberts, A. C., Hodges, J. R., Summers, B. A., Polkey, C. E., \& Robbins, T. W. (1993). Contrasting mechanisms of impaired attentional set-shifting in patients with frontal lobe damage or Parkinson's disease. Brain, 116, 1159-1175.

Packard, M. G., Hirsh, R., \& White, N. M. (1989). Differential effects of fornix and caudate lesions on two radial maze tasks: Evidence for multiple memory systems. Behavioral Neuroscience, 106, 439-446.

Paulsen, J. S., Butters, N., Salmon, D. P., Heindel, W. C., \& Swenson, M. R. (1993). Prism adaptation in Alzheimer's and Huntington's disease. Neuropsychology, 1, 73-81.

Perruchet, P., \& Pacteau, C. (1990). Synthetic grammar learning: Implicit rule abstraction or explicit fragmentary knowledge? Joumal of Experimental Psychology: General, 119, 264-275.

Petit, H., \& Milbled, G. (1973). Anomalies of conjugate ocular movements in Huntington's chorea: Application to early detection. In A. Barbeau, T. N. Chase, \& G. W. Paulson (Eds.), Advances in neurology: Vol. 1. Huntington's chorea, 1872-1972 (pp. 287-294). New York: Raven Press.

Pillon, B., Deweer, B., Agid, Y., \& Dubois, B. (1993). Explicit memory in Alzheimer's, Huntington's and Parkinson's diseases. Archives of Neurology, 50, 374-379.

Reber, A. S. (1976). Implicit learning of synthetic languages: 'The role of instructional set. Joumal of Experimental Psychology: Human Learning and Memory, 2, 88-94.

Reber, A. S. (1989). Implicit learning and tacit knowledge. Journal of Experimental Psychology: General, 118, 219-235.

Saint-Cyr, J. A., Taylor, A. E., \& Lang, A. E. (1988). Procedural learning and neostriatal dysfunction in man. Brain, 111, 941-959.

Salmon, D. P., \& Butters, N. (1995). Neurobiology of skill and habit learning. Current Opinion in Neurobiology, 5, 184-190.
Salmon, D. P., Shimamura, A. P., Butters, N., \& Smith, S. (1988). Lexical and semantic priming effects in patients with Alzheimer's disease. Journal of Clinical and Experimental Neuropsychology, 10, 477-494.

Schacter, D. L., Alpert, N. M., Savage, C. R., Rauch, S. L., \& Albert, M. S. (1996). Conscious recollection and the human hippocampal formation: Evidence from positron emission tomography. Proceedings of the National Academy of Sciences USA, 93, 321-325.

Schacter, D. L., Chiu, C.-Y., \& Ochsner, (1993). Implicit memory: A selective review. Annual Review of Neuroscience, 16, 159-182.

Schacter, D. L., Cooper, L. A., Tharan, M., \& Rubens, A. B. (1991). Preserved priming of novel objects in patients with memory disorders. Journal of Cognitive Neuroscience, 3, 118-131.

Servan-Schreiber, E., \& Anderson, J. R. (1990). Learning artificial grammars with competitive chunking. Journal of Experimental Psychology: Learning, Memory, and Cognition, 16, 592-608.

Shimamura, A. P., Salmon, D. P., Squire, L. R., \& Butters, N. (1987). Memory dysfunction and word priming in dementia and amnesia. Behavioral Neuroscience, 101, 347-351.

Shoulson, I., \& Fahn, S. (1979). Huntington's disease: Clinical care and evaluation. Neurology, 29, 1-3.

Sotrel, A., Paskevich, M. A., Kiely, D. K., Bird, E. D., Williams, R. S., \& Myers, R. H. (1991). Morphometric analysis of the prefrontal cortex in Huntington's disease. Neurology, 41, 1117-1123.

Spargo, E., Everall, I. P., \& Lantos, P. L. (1993). Neuronal loss in the hippocampus in Huntington's disease: A comparison with IIIV infection. Joumal of Neurology, Neurosurgery, and Psychiatry, 56, $487-491$.

Squire, L. R. (1987). Memory and brain. New York: Oxford University Press.

Squire, L. R., \& Knowlton, B. J. (1995). Learning about categories in the absence of memory. Proceedings of the National Academy of Sciences, USA, 92, 12470-12474.

Squire, L. R., Knowlton, B. J., \& Musen, G. (1993). The structure and organization of memory. Annual Review of Psychology, 44, 453-495.

Squire, L. R., \& McKee, R. (1992). Influence of prior events on cognitive judgments in amnesia. Joumal of Experimental Psychology: Learning, Memory, and Cognition, 18, 106-115.

Squire, L. R., Ojemann, J. G., Miezin, F. M., Petersen, S. E., Videen, T. O., \& Raichle, M. E. (1992). Activation of the hippocampus in normal humans: A functional anatomical study of memory. Proceedings of the National Academy of Sciences, USA, 89, 1837-1841.

Squire, L. R., Zola-Morgan, S., \& Chen, K. (1988). Human amnesia and animal models of amnesia: Performance of amnesic patients on tests designed for the monkey. Behavioral Neuroscience, 11, 210-221.

Tulving, E. \& Schacter, D. (1990, January 19). Priming and human memory systems. Science, 247, 301-306.

Vonsattel, J. P., Myers, R. H., Stevens, T. J., Ferrante, R. J., Bird, E. D., \& Richardson, E. P., Jr. (1985). Neuropathological classification of Huntington's disease. Journal of Neuropathology and Experimental Neurology, 44, 559-577.

Wang, J., Aigner, T., \& Mishkin, M. (1990). Effects of neostriatal lesions on visual habit formation in rhesus monkeys. Society for Neuroscience Abstracts, 16, 617.

Willingham, D. B., \& Koroshetz, W. J. (1993). Evidence for dissociable motor skills in Huntington's disease patients. Psychobiology, 21, 173-182.

Willingham, D. B., Koroshetz, W. J., \& Peterson, E. W. (1996). Motor skills have diverse neural bases: Spared and impaired skill acquisition in Huntington's disease. Neuropsychology, 10, 315-321.

Received January 2, 1996

Revision received April 22, 1996 Accepted April 24, 1996 